The focus of this paper is the development programme, which involves a multi-day structured off-site course and a series of workplace activities, including participation in an action learning group, a coaching relationship, two shadowing opportunities and a workplace project. Both course and workplace activities relate to five focus areas that reflect themes common to other health leadership frameworks (Dickson, 2007; Health Workforce Australia, 2013; NHS Institute for Innovation and Improvement, 2010) as illustrated in Table 1.

The Tasmanian health leadership framework themes were incorporated into the development programme in the following manner:

1. Strategic Focus presentations provide context and organisational awareness, a greater understanding of strategic directions and current challenges, with an opportunity to directly engage with senior leaders. This is reinforced by the workplace activity of shadowing.

2. Achieving Results presentations provide factual information about finance and human resource management systems. Workplace projects are often aligned to this focus.

3. Quality and Governance presentations provide national and policy context for local work to improve the safety and quality of services. Coaching relationships also provide a quality assurance function during the workplace activities.

4. Managing People presentations provide context and organisational awareness that enables participants to reflect on their management practice and team dynamics. Action learning groups also often focus on this theme.

5. Leadership and Self-development presentations share leadership stories and examples and provide preparation for post-course activities.

A causal theory associated with positive organisational behaviour (Luthans, 2002a; 2002b) was adopted to underpin the DHHS development programme, aligned with the self-assessment instruments used by participants during the off-site course. The Competing Values Management Survey (Edwards, Austen \& Altpeter, 1998; Quinn, 1988), the Organizational Culture Survey (Quinn, 1988; Van Beek \& Gerritsen, 2010) and the Fundamental Leadership Survey (Quinn, 2005) formed the backbone of participant selfassessment of their individual management and leadership styles and their interaction with DHHS organisational culture.

As positive organisational behaviour is developmental, dealing with psychological 'states' rather than 'traits', this selfassessment is posited to be open to revision through changes in three sets of resources: agentic, relational and affective (Roberts, Dutton, Spreitzer, Heaphy \& Quinn, 2005). Agentic resources include a sense of self-efficacy and an ability to positively envision oneself in the future. Relational resources are the result of positive interpersonal relationships that provide social and emotional support within the workplace. Affective resources include all positive emotions and, in the work setting, include positive orientation towards the job (Roberts et al., 2005). Changes in these resources, over time, provide target outcomes for evaluation. The evaluation of the DHHS leadership development programme was based on the concepts behind these self-assessment instruments.

\section{Research purpose}

Few leadership development programmes have an explicit causal theory - an explanation of how and why the development activities would lead to outcomes and impacts - and most evaluate short-term outputs only, such as participant numbers and satisfaction with the programme (Russon \& Reinelt, 2004). Literature providing a meta-evaluation of workplace leadership development programmes (Development Guild/DDI, 2002; Hannum, Martineau \& Reinelt, 2007) provides guidance for new programmes but does not provide a single preferred method. Instead, Hannum et al. (2007, p. 4) suggest that: 'different leadership development programs, different organizational or community contexts, and different evaluation questions demand a broad variety of approaches'.

The aim of this evaluation was to determine whether DHHS staff experienced an increase in their agentic, relational and affective resources following participation in the DHHS development programme. The alignment of the DHHS development programme with positive organisational behaviour and the work of Roberts et al. (2005) led to a search for associated (quantitative) evaluation instruments. The evaluation methodology most associated with positive organisational behaviour, the Psychological Capital Questionnaire (PsyCap) (Luthans, Youssef \& Avolio, 2007a), shares an interest in self-efficacy and an optimistic view of the future. Whilst addressing affective resources in terms of seeing hope as a key concept, PsyCap does not explicitly include relational resources in the remaining key concept of resilience (Avolio, Luthans \& Youssef, 2007).

An examination of those leadership programmes that had used the advanced levels of evaluation associated with the Kirkpatrick evaluation framework (Kirkpatrick, 1994, cited in McLean \& Moss, 2003) indicated an 'inverse relationship' between effort and results. The 'substantial costs' associated

TABLE 1: Main components of health leadership frameworks compared.

\begin{tabular}{llll}
\hline Tasmanian & Australian & Canadian & United Kingdom \\
\hline Strategic Focus & Shapes Systems & Systems Transformation & Setting Direction Creating the Vision \\
Achieving Results & Achieves Outcomes & Achieve Results & Delivering the Strategy \\
Quality and Governance & Drives Innovation & Develop Coalitions & Improving Services \\
Managing People & Engages Others & Engage Others & Working with Others Managing Services \\
Leadership and Self-development & Leads Self & Lead Self & Demonstrating Personal Qualities \\
\hline
\end{tabular}


with this form of leadership programme evaluation (McLean \& Moss, 2003) made it unsuitable for evaluation of the DHHS development programme. The Leadership Programme Outcomes Measure (Black \& Earnest, 2009), associated with the EvaluLEAD framework (Grove, Kibel \& Haas, 2005) also presents an expanded evaluation agenda, requiring the measurement of 'community outcomes' of leadership development. In order to adequately capture the change in the target outcomes of the evaluation, in a manner that could be undertaken within existing resources, it was necessary to develop a leadership development programme evaluation tool. It needed to be suitable for use in the health and human services sector and extend beyond short-term satisfaction measures to capture outcomes over time.

\section{Contribution of the study}

Through the development of a leadership development evaluation tool explicitly linked to the work of Roberts et al. (2005), the results of this study contribute to the body of knowledge associated with positive organisational behaviour. To the extent that this study presents the results of an evaluation over time, it contributes to the understanding of workplace leadership development programmes. The placement of this work in health and human services is significant for leadership development in the sector. The rest of this article describes the contextual environment, research design, responses, results and findings of the development programme evaluation. It then discusses the implications these have for this and other leadership development programmes.

\section{Literature review}

\section{Health services: A challenging fiscal environment}

One of the most significant challenges facing the delivery of health services is the increasing cost of care. International comparisons of health care cost are commonly described as the percentages of gross domestic product (GDP) taken up by total health expenditure. Comparisons between countries within the OECD show health spending growth has surpassed GDP growth by almost two to one over the last decade (OECD, 2011). Due to the global economic recession, this trend has increased since 2008 and has increased pressure on health service providers to eliminate 'wasteful spending' and demonstrate value for money (WHO, 2010).

Within Australia, public hospitals, medical services and pharmaceuticals make up the majority of health-related expenditure, whilst the national government provides the majority of the funds (Australian Institute of Health and Welfare, 2012). Prior to 2012, the majority of funds were provided to state and territory governments, to be allocated to hospitals and other health services. These historically based allocations had not kept up with demand or cost increases. In 2012, through the National Health Reform Agreement, the Australian government initiated a major restructure of the health system and the introduction of new 'activity-based' funding arrangements (Council of Australian Governments, 2011).
In Tasmania, as in many other states and territories, government expenditure has been increasingly limited. In recent years this resulted in organisational downsizing within publicly funded health services of approximately $10 \%$ (O’Byrne, 2011; 2012). An environment of organisational downsizing and restructuring has been shown to have negative impacts on workplace physical and psychological health (Emmerik \& Euwema, 2008; European Expert Group on Health in Restructuring, 2009; Lee \& Teo, 2005; Swanson \& Power, 2001).

The link between cost issues and health services leadership works two ways, both cause and effect. Whilst health service providers are not primarily focused on financial matters (Shannon, Holden \& Van Dam, 2012), they are significant drivers of cost in that they determine what procedures and equipment is required for patient treatment (Kosimbei, Hanson \& English, 2011). Health service providers are also impacted by cost reductions associated with organisational downsizing and restructuring (Shannon, Van Dam \& Stokes, 2012). The distributed model of leadership active within health services provides a challenging context for the organisation.

\section{Health services leadership development and positive organisational behaviour}

The 'fit' between health services leadership development programmes and positive organisational behaviour is the link with self-efficacy and resilience, the proactive and reactive responses of the individual within a workplace context (Luthans, 2002a). On one hand, individuals who work as health professionals are expected to be highly qualified, with considerable expertise and experience. Their work requires the ability to successfully act on their environment (Braithwaite et al., 2011). On the other hand, a higher level of responsibility, and the constant 'crisis' in health services, due to fiscal and other pressures, flag the need for resilience. The study of positive organisational behaviour provides both understanding and strategies in a less-than-positive environment (French \& Holden, 2012).

The concept of positive organisational behaviour is particularly significant for health services. The contemporary model of health services leadership is that of a 'distributed' (Bolden, 2011) or 'post-heroic' leadership style, which recognises that leaders exist at all levels and in all occupational streams within an organisation. In this context, systematic leadership development across the organisation results in an 'empowered organisation' (Hancock \& Campbell, 2006). It is in this sense also that the difference between 'positive organisational behaviour' (with its 'micro' focus on individual development) and 'positive organisational scholarship' (focused on 'macro' organisational issues) (Luthans, Youssef \& Avolio, 2007b) becomes less relevant.

\section{Research design Research approach}

A mixed-method approach was taken, drawing inferences from quantitative and qualitative data in order to explore, 
examine and understand the contextual world of leadership development (Doyle, Brady \& Byrne, 2009; Leech \& Onwuegbuzie, 2009). Whilst mixed-method research is becoming recognised as the third major research approach along with qualitative research and quantitative research (Johnson, Onwuegbuzie \& Turner, 2007), it is a broad category that can include a range of research strategies. The authors followed a mixed-method approach that involved triangulating the descriptive data that emerged from questionnaire surveys and semi-structured interviews (Kvale, 1996).

The qualitative research component of this study was based in constructivist grounded theory (Charmaz, 2006). This approach allows participant reflections on personal experience to shape the explanatory categories that are used to analyse that experience. In this study, open-ended questions within semi-structured interviews provided a participant 'reality check' for the quantitative results emerging from closed-question survey data (Jick, 1979). The authors are 'pragmatic researchers' (Onwuegbuzie \& Leech, 2005), who rely on their research findings to inform their delivery of leadership and management development programmes.

\section{Research method}

A participant satisfaction survey captured initial responses to individual speakers and topics presented at the development programme course, as a form of process evaluation. The outcomes evaluation of the DHHS leadership development programme involved an online evaluation survey administered twice: initial (T1) data was collected two weeks before the development programme course and subsequent (T2) data was collected nine months after the course, when most participants would have completed all the workplace activities. In addition, a small number of interviews were undertaken between one and two years after the development programme course, to provide longer-term reflections on the impact of the programme.

\section{Participants}

The evaluation target population were participants in the development programme courses held between February

TABLE 2: Gender of the Tasmanian Department of Health and Human Services staff, participants.

\begin{tabular}{lll}
\hline Category & Male (\%) & Female (\%) \\
\hline Department of Health and Human Services & 25 & 75 \\
Participants & 24 & 76 \\
T1 & 23 & 77 \\
T2 & 19 & 82 \\
\hline
\end{tabular}

$\mathrm{T} 1$, the pre-course baseline outcomes survey; $\mathrm{T} 2$, the nine-month outcomes survey. and November $2011(n=205)$. These were broadly reflective of the gender ratio of DHHS, with a predominance of female employees (Department of Health and Human Services, 2012), and employees classified under the Administration and Clerical Workers Industrial Award. There was some over-representation of Allied Health professionals amongst development programme participants. This breakdown is shown in Table 2 and Table 3. The pre-course baseline outcomes survey (T1) attracted a $65 \%$ response rate $(n=134)$, the post-course participant satisfaction survey was filled out by 118 participants (58\%), and the nine-month outcomes survey (T2) had a $42 \%$ response rate $(n=87)$. Men were less likely to complete the nine-month outcomes survey than were women.

\section{Ethical considerations}

All participants in the evaluation participated voluntarily. Information about the research was provided to all participants in the development programme and it was up to the participants whether they wished to 'opt in' to the research. Responses to the quantitative data gathering were anonymous. Qualitative data (interviews) were de-identified. Electronic copies of interview and survey data were kept in a password-protected folder. Data gathering was approved by the Human Research Ethics Committee (Tasmania, Australia) Network, permit number H12103.

Purposive sampling was used to select interview participants who had completed the development programme and reflected the gender and professional background of DHHS staff and development programme participants. Potential participants were emailed information about the evaluation and asked if they would like to take part. If they agreed, a meeting room within the DHHS precinct provided an interview setting. Of the 35 participants who were initially approached, nine participants agreed to take part. Table 4 presents the biographical data of interview participants.

\section{Measuring instruments}

Participant satisfaction survey for immediate responses: A participant feedback form was provided at the start of each development programme course so that responses to presentations and exercises could be recorded in 'real time' or at the end of each day. Participants were requested to transfer their anonymous responses to the online questionnaire the week after their participation in the course. Whilst it was possible for participants to alter their paper responses when transferring them to the online questionnaire, they were requested to simply provide those initial reactions.

The purpose of the survey was to gain participant opinion on whether the agenda of the development programme course

TABLE 3: Professional profiles of Department of Health and Human Services staff, participants.

\begin{tabular}{|c|c|c|c|c|c|}
\hline Category & Administrative and clerical (\%) & Allied health (\%) & Ambulance (\%) & Medical (\%) & Nursing and midwifery (\%) \\
\hline Department of Health and Human Services & 40 & 12 & 7 & 3 & 36 \\
\hline Participants & 37 & 21 & 5 & 1 & 36 \\
\hline $\mathrm{T} 1$ & 39 & 17 & 5 & 2 & 36 \\
\hline T2 & 35 & 22 & 1 & 1 & 33 \\
\hline
\end{tabular}

$\mathrm{T} 1$, the pre-course baseline outcomes survey; $\mathrm{T} 2$, the nine-month outcomes survey. 
had met their needs and to provide feedback to the senior executives who had spoken as presenters. Of particular interest to the evaluation, however, were participants' freetext comments as to what aspect of the course they found most useful and their level of agreement with the statement that the development programme course will be of value to my management and leadership practice' in (1) their current job and in (2) their future career. Here respondents were given a choice of 'strongly disagree', 'disagree', 'agree', 'strongly agree'.

Outcomes evaluation survey for medium-term responses: The outcomes evaluation survey incorporated the 10item General Self-Efficacy Scale (GSES) (Schwarzer \& Jerusalem, 1995) and the four-item Berlin Social Support (Instrumental Perceived Available Support) Scale (BSSS) (Schulz \& Schwarzer, 2003), together with one question relating to positive job orientation. The response options for each question of 'not true', 'hardly true', 'moderately true' and 'exactly true' in the T1 and T2 surveys were assigned numeric values of 1, 2, 3 and 4 respectively. Commercially available online software was used to administer the outcomes evaluation survey in a way that ensured anonymity of responses. An email was sent to participants requesting their participation in the survey and giving the URL of the survey website. Two weeks later, another email was sent to participants, reminding them of the survey availability.

The GSES has been validated in a wide range of contexts (Liu \& Lee, 2012; Scholz, Dona, Sud \& Schwarzer, 2002) and has demonstrated internal consistency (Cronbach's alpha values of between 0.75 and 0.91 ). This study sample resulted in a Cronbach's alpha of 0.81 . The sum mean for the GSES in this study was 32.54 with a standard deviation of 3.15. Studies with larger and more diverse populations have reported sum means ranging between 23.52 and 33.44 with a standard deviation of 4.00 to 5.42 (Luszczynska, Scholz \& Schwarzer, 2005; Schwarzer, Bäßler, Kwiatek, Schröder \& Zhang, 1997).

\begin{tabular}{llll}
\multicolumn{2}{l}{ TABLE 4: Interview participant details. } \\
$\begin{array}{l}\text { Participant } \\
\text { number }\end{array}$ & Position & Gender & Professional background \\
\hline P1 & $\begin{array}{l}\text { Health reform } \\
\text { manager }\end{array}$ & Male & Allied health \\
P2 & Project manager & Female & Administrative and clerical \\
P3 & Nurse unit manager & Female & Nursing and midwifery \\
P4 & Area manager & Female & Nursing and midwifery \\
P5 & Project officer & Female & Administrative and clerical \\
P6 & Manager & Male & Administrative and clerical \\
P7 & Registered nurse & Female & Nursing and midwifery \\
P8 & Contract manager & Female & Administrative and clerical \\
P9 & $\begin{array}{l}\text { Safety and quality } \\
\text { consultant }\end{array}$ & Female & Nursing and midwifery \\
\hline
\end{tabular}

P, participant.
The BSSS measures the level of tangible (material, physical or mental) support that the respondents anticipate will be available to them, should they require it (Schwarzer \& Leppin, 1988). Previously, the subscale has shown a Cronbach's alpha of 0.83 (Kapikiran \& Kapikiran, 2010; Schulz \& Schwarzer, 2003); for this study the Cronbach's alpha value was 0.79 . Sum means were not published.

The evaluation questionnaire used in this study, made up of the two instruments described above combined with an additional question on job satisfaction, show an internal consistency of 0.83 and standard deviation of 4.54 . These descriptive statistics are provided in Table 5.

Participant interviews for longer-term reflections: The qualitative research set out to evaluate changes in leadership and management behaviours after participation in the DHHS development programme through a series of semi-structured interviews. The timing of these interviews was determined by the availability of a graduate trainee, a qualified social worker, who was trained to undertake the interviews as part of her work. Temporarily attached to the programme team, she was able to gather data that was not influenced by the presence of established programme staff.

The interviews were organised around a set of predetermined open-ended questions, with other questions emerging from the dialogue between interviewer and interviewee (DiCicco-Bloom \& Crabtree, 2006). Participants were asked to describe their day-to-day role within the DHHS, whether it had changed since they participated in the development programme, or whether their feelings about it had changed. They were also asked about the workplace activities and the academic programme that followed the multi-day course. This process of reflection, rephrasing and probing allowed for unanticipated responses and issues to emerge (Tod, 2006), with the focus on letting the story, as 'owned' by the interviewee, to surface. Each interview took at least an hour, was recorded, transcribed by the graduate trainee and returned to the participant for quality assurance. Only when the transcription was returned with approval was it added to the data file for further analysis.

\section{Data analysis and reporting}

Data were analysed through systematic grounded theory techniques (Charmaz, 2006). The researchers reviewed the emerging themes separately then discussed their ideas. During the analysing process of the qualitative component, notes were kept in the form of memos, which described the researcher's impressions, ideas and perceptions. The data was coded and sorted, leading to the discovery of themes (Charmaz, 2006). A set of six themes emerged from the data for further exploration and reporting.

TABLE 5: Descriptive statistics for outcomes evaluation questionnaire subscales.

\begin{tabular}{llll}
\hline Measure & 10-tem General Self-Efficacy Scale & $\begin{array}{l}\text { Four-item Berlin Social Support (Instrumental } \\
\text { Perceived Available Support) Scale }\end{array}$ & 15-term evaluation questionnaire \\
\hline Cronbach's alpha & 0.81 & 0.79 & 0.83 \\
Sum mean & 32.54 & 13.21 & 49.15 \\
Standard deviation & 3.15 & 1.91 & 4.54 \\
\hline
\end{tabular}




\section{Results and findings Evaluation survey results}

Agentic resources (General Self-Efficacy Scale): The itemlevel statistics for the GSES are listed in Table 6. The mean scores for each item at T1 (prior to attending the development programme course) and T2 (nine months following the development programme course) are listed. These item-level means fall within the range of means recorded in previous cross-national research (Liu \& Lee, 2012; Scholz et al., 2002) with the exception of one item: 'I am confident that I could deal efficiently with unexpected events' scored higher $(\mathrm{M}=$ $3.49)$ in this study than in previous studies $(\mathrm{M}=3.40)$.

Strong results $(P<0.01)$ included an increase in the ability to overcome opposition, an increase in a sense of resourcefulness, coping abilities and problem solving. Moderate results $(P$ $<0.05)$ included increases in the ability to solve difficult or intractable problems, and the ability to deal with unexpected events or issues. A weak increase $(P<0.1)$ was evident in the response to finding solutions to troubles. There was no statistical support $(p>0.1)$ for the statement that it was 'easy' to achieve aims and goals. The overall response, however, indicated a moderate rise in general self-efficacy over time.

Relational resources (Berlin Social Support Scale, Perceived Instrumental Support): The BSSS results are listed in Table 7. One significant result $(P<0.01)$ was around the availability of helpful people. Moderate results $(P<0.05)$ included the availability of reliable people, and assistance when overwhelmed by demands. There was no statistical support $(p>0.1)$ for an increase in support for dealing with worries. A weak increase $(P<0.1)$ was evident in the overall response to the scale, indicating that a slight improvement in social support may have occurred over time.
Affective resources in the workplace: Table 8 illustrates that there was no support for an increase in positive orientation towards the job in the quantitative results.

\section{Interview results}

Increasing confidence: The nine participants who consented to further interviews described a sense of increasing confidence following their participation in the development programme course. Reflecting on their experience over this time, they recalled that this sense intensified as they progressed through the work-based activities. Box 1 provides verbatim extracts that illustrate this theme.

Creating a positive environment: The theme of creating a positive environment relates to the construction of an optimistic work milieu in spite of difficult circumstances emerging within the participants' professional lives. During the course of this research, as a result of diminishing funding, the DHHS workforce changed and many employees on a fixed-term contract left the organisation. In addition, through intensive restructuring initiatives, certain positions became redundant. All participants in the programme in some way were affected by this change. Even within a less-than-positive organisational environment, however, participants were able to feel somewhat optimistic, as shown by comments in Box 2 .

Finding networks: The development programme gave participants the opportunity to find and connect with other staff within a large organisation. This most often described as finding networks. In the participant satisfaction survey, of the 110 separate comments on the 'most valuable part' of the course, 'networking' was mentioned 28 separate times, the strongest single theme. This benefit persisted over time as they progressed through the workplace activities of action

TABLE 6: Results for the General Self-Efficacy Scale: Item-level statistics.

\begin{tabular}{|c|c|c|c|c|}
\hline Item text & $\mathrm{T} 1(\mathrm{M})$ & $\mathrm{T} 2(\mathrm{M})$ & Change & Significance ( $p$-value) \\
\hline I can remain calm when facing difficulties because I can rely on my coping abilities. & 3.17 & 3.46 & +0.29 & Strong $(<0.001)$ \\
\hline Thanks to my resourcefulness, I know how to deal with unforeseen situations. & 3.22 & 3.41 & +0.19 & Strong (0.002) \\
\hline When I am confronted with a problem, I can usually find several solutions. & 3.14 & 3.33 & +0.19 & Strong $(0.004)$ \\
\hline If someone opposes me, I can find the means and ways to get what I want. & 2.72 & 2.91 & +0.19 & Strong (0.005) \\
\hline I can usually handle whatever comes my way. & 3.34 & 3.49 & +0.15 & Moderate (0.015) \\
\hline I am confident that I could deal efficiently with unexpected events. & 3.34 & 3.49 & +0.15 & Moderate (0.015) \\
\hline I can solve most problems if I invest the necessary effort. & 3.42 & 3.56 & +0.14 & Moderate $(0.020)$ \\
\hline I can always manage to solve difficult problems if I try hard enough. & 3.18 & 3.31 & +0.13 & Moderate (0.021) \\
\hline If I am in trouble, I can usually think of a solution. & 3.34 & 3.45 & +0.11 & Weak (0.052) \\
\hline It is easy for me to stick to my aims and accomplish my goals. & 3.08 & 3.14 & +0.06 & NS* $(0.208)$ \\
\hline Scale & 3.21 & 3.36 & +0.15 & Moderate $(0.033)$ \\
\hline
\end{tabular}

M, mean; NS*, not significant.

TABLE 7: Results for the Berlin Social Support Scale (instrumental perceived available support): Item-level statistics.

\begin{tabular}{|c|c|c|c|c|}
\hline Item text & $\mathrm{T1}(\mathrm{M})$ & $\mathrm{T} 2(\mathrm{M})$ & Change & Significance ( $p$-value) \\
\hline There are people who offer me help when I need it & 3.22 & 3.43 & +0.21 & Strong (0.008) \\
\hline When everything becomes too much for me to handle, others are there to help me. & 3.13 & 3.29 & +0.16 & Moderate (0.029) \\
\hline I know some people upon whom I can always rely. & 3.46 & 3.59 & +0.13 & Moderate (0.046) \\
\hline When I am worried, there is someone who helps me. & 3.16 & 3.24 & +0.08 & NS* (0.199) \\
\hline Scale & 3.24 & 3.38 & +0.15 & Weak (0.096) \\
\hline
\end{tabular}

M, mean; NS*, not significant. 
learning, coaching and shadowing. Establishing networks led to the realisation that the issues faced in one area were, at times, common to other managers. Listening to what other managers and leaders were doing, trying to share what was happening in the bigger world and using that information led to a rich experience for participants. Box 3 substantiates this with direct quotations from the interviews.

Notable people: The term notable people refers to those peers and senior staff with whom participants were engaged during the development programme. Initially this occurred when senior managers presented at the development programme course. Within the participant satisfaction survey, this emerged in a number of ways, in references to the 'presenters', 'presentations', 'strategic' and 'leader', and was the second-strongest theme evident in the initial participant responses. Participants found it invaluable that the most senior people in the organisation would give the time to share their stories with them in how they manage and lead.

Later on, connection with notable people occurred through work-based activities such as coaching and shadowing. This was one of the enduring themes of the study: a greater sense of ownership of the strategic direction held by senior management and, at the same time, an increase in the ability to understand challenges faced by those 'in power'. Box 4 shows this impact.

Broadening horizons: The notion of broadening horizons described participants being able to create a view larger than their immediate work group. It involved moving from a dayto-day point of view to acquiring a strategic view in relation to managing the service. Many participants indicated that they had been working in 'silos' and that they possessed a limited understanding of the broader DHHS work environment. Their participation in the development programme gave them a chance to look beyond their own unit. The direct quotes in Box 5 lend support to the importance of this theme.

Clarifying career options: The concept of clarifying career options relates to participants having established a sense of direction regarding their career path. This sense of career clarification was something that was evident almost immediately amongst development programme participants. In the post-course satisfaction survey, $98 \%$ of the participants agreed that the programme would be of value to their management and leadership practice in their current position: $45 \%$ agreed and 53\% strongly agreed. At the same time, however, $99 \%$ participants believed that the programme would be even more useful in their future career development: $31 \%$ agreed and 68\% strongly agreed. The increased levels of confidence reported by participants meant that they were looking beyond their current role, rather than becoming more satisfied in it. However, some participants reflected on their career and came to the conclusion that, even if they were looking for something new, they would not like to be in a non-clinical position. Examples of both results are shown in Box 6.
TABLE 8: Job orientation

\begin{tabular}{llccl}
\hline Item text & T1 (M) & T2 (M) & Change & $\begin{array}{l}\text { Significance } \\
(p \text {-value })\end{array}$ \\
\hline Iget a lot of satisfaction from doing my job. & 3.35 & 3.38 & +0.05 & NS* $^{*}(0.382)$ \\
\hline
\end{tabular}

$M$, mean; NS*, not significant.

BOX 1: Increasing confidence.

P1: '[the course helps you ] be more confident in your role and what you have to do. ... You know, be entrepreneurial, put yourself out there.'

P2: 'I feel a lot more confident within myself I guess and my ability where I didn't before. I just saw myself as a little project officer and you know in my own little world ... it's sort of given me more confidence to think about where I could head in the future.'

P5: 'My confidence just kept growing and growing about my ideas that I had and things that I was talking about [sic].'

P7: 'The course, it [sic] has given me the skills and the confidence and understanding behind the theory about the way that we actually do things.'

P8: '[It] really reassured me that I did a really good job and that I was actually a good manager.'

P9: 'I think as a person and as a professional I feel I've grown in my own confidence in myself. That's given me the confidence to perhaps be riskier in my approaches and a bit more challenging in my approaches to situations or complex problems.'

BOX 2: Creating a positive environment.

P1: 'I guess my response would be, in the face of difficult problems, less an inclination to isolate, or to kind of nut it through or just go it's all too hard and more the capability to connect with other people and look at solving problems [sic]

P4: 'We've got our model of care, which is just one big, fat, change management programme, right ... and we are right in the middle of it and we're just doing the work. So to have been to the [course] and talked about change and bringing people along with change ... it just gives me some head space to go "you know that this is a process" ... it's good to lift your head up a bit.'

P5: 'The [course] for me was the beginning of a - this may sound a little melodramatic - but the beginning of a new life in government."

P6: ' $[/] \mathrm{t}$ made me feel better about the state service as a whole you know that we're all people you know trying to do a job [sic].'

P8: 'When I did the course the week before there was some budgeting stuff going on and there were talks of cuts and ... I was really worried I was going to lose my job ... I think it helped me feel a little bit more secure in my role ... and be willing to explore other opportunities if things did go sour here.'

\section{BOX 3: Finding networks.}

P1: 'I think one of the things that comes through from [the course] is that there are multiple strategies and approaches that you learn in terms of mentoring, creating a network through an action learning group, a cadre of peers [sic].'

P2: 'We had a really broad group from across health and human services and that really sparked a lot of networking. A lot of us are studying together now.'

P3: 'The person I had as a coach is still in the building I' $m$ working in so even though that was a long time ago I've still got that relationship that I can still pop my head in and ... have a bit of a discussion and whatever [sic], so that's been really useful as well.

P4: 'One of the advantages has been contacts within $[D H H S]$... That linkage with peers was really helpful.'

P5: 'The action learning set still goes - after two years - quite a lot of the time we're there to support each other [sic].

P6: 'To know that I've got a group of peers out there that I can ask questions of and that we're all coming from a common level and a common point of view human resources, lack of money, perceived lack of understanding, not enough hours in the day, they are issues that we all face."

P7: 'I have ... experienced some wonderful networking opportunities within that ... course and I made some very solid friendships and some work colleagues who I'd never met before and now they've become critical companions to myself in terms of bouncing off ideas, sharing thoughts, and for all three of us, actually, it has become quite a valuable asset [sic].' 


\section{BOX 4: Notable people.}

P1: 'Hearing the unvarnished, attenuated, unchanged message of the leaders is really, really powerful... You have heard it from the top level and you have been really, really powerful... You have heard it from the top level and you have been
directed and you have been given permission. You have been told this is where we are headed and I think that, that's a significant part of the impact [sic].'

P2: II was really impressed with pretty much well all the speakers. I just found they were a really good mix of speakers, really strong leaders and they gave us a really good idea of what is going on in other parts of the [DHHS].

P3: 'I really liked her presentation and found that a lot of what she was saying about the change, how she had managed change really resonated with what was to come for me [sic]. Knowing that it was coming ... I actually had a chat with her at lunch time on that particular day and you know we talked about stuff and she said here's my phone number and give me a call if you need to chat about anything... which I didn't ever ... but just knowing that there was somebody there ... I found that really useful [sic].'

P4: 'All the aspects of shadowing and coaching and they were all great but the opportunity to shadow at a higher level was really good ... was really helpful really good to have access to such a high level leader.

P6: 'On a personal note I remember [the Director of Public Health] giving a presentation about the state of Tasmanians. I think that was on the second day. That was the day I stopped smoking after his discussion. ... So that really hit home to me. So yes it's been over a year since I stopped smoking because of that presentation. So that in itself personally was a significant achievement.'

P7: 'Shadowing a regional manager allowed me to sit and look at the skills that she used.... We went to a couple of industrial meetings which was very interesting at this time of change. The emotions of the people around the table ... you could allow yourself to be drawn into that but [she] was very professional. It was very powerful, very engaging.'

P9: I saw them presenting and ... I do feel privileged that I've got a bit of insight into "a day in the life of ..." I haven't walked in their shoes but I've seen that ... it's extremely challenging $[$ sic]. There were people there in the leadership panel that had to make some very challenging decisions that weren't going to win friends.'

\section{BOX 5: Broadening horizons.}

P1: 'The thing that the course really gave me was the context within which we are currently operating and I think that kind of environmental scan is really, really useful.'

P2: 'I think a bit more "bigger picture" on things since I have done the course. I think that has put things in a bit more context as well. Particularly hearing from what's going on in different areas in the [DHHS], I am sort of a lot more in tune with that now and thinking OK even though we are just part of the whole picture, what else is happening outside that we can link in with, what we are doing [sic]. So it has given me a bit more of a strategic focus.'

P3: '[Shadowing] was actually really useful ... to get that overview of kind of ou whole department rather than just [by team's] perspective was really useful and to just see what pressures he's under and the whole office [sic].'

P4: 'When you work in any department ... you are just focused on that work and surrounded by the people who deliver that work. It was good to broaden the surrounded by the people who deliver that work. It was good to broaden the
horizons and talk to somebody who was in an acute setting or in the ambulance service.'

P8: 'Not having been in [DHHS] very long and never worked for the government, I found it really good to have a broader overview of how everything worked.'

P9: 'Being alongside people who work in settings other than health I think has given me a very much broader perspective [sic].'

\section{Triangulating the data}

Table 9 provides a broad overview of the results from this study, with strong and moderately significant quantitative results (as indicated by $p$-values) from the survey questionnaires aligned with the six qualitative themes that emerged from the data through the application of constructivist grounded theory techniques.

\section{Discussion}

The purpose of this research was to determine whether DHHS staff experienced an increase in target outcomes based on the Roberts et al. (2005) 'three resources' model. In order
BOX 6: Clarifying career options.

P2: 'I guess I didn't realise until I did the course how much project management that I do every day. I knew that I did a lot of projects but didn't actually realise how much I do manage by myself. So that was a bit of an eye opener and I guess the course put that in context. Since then I have put all of this in my [performance development agreement] and met with my manager. I guess I would just like to be development agreement and met with my manager.
able to broaden those skills of project management.'

P3: 'I think that was something that the programme probably helped clarify for me ... I was not sure if perhaps that might be the career path ... but I think it probably clarified that for me that I won't to be able to maintain some clinical component [sic]. I don't want to be a bureaucrat.'

P5: 'One thing that I have discovered out of all of this ... I have been managing for a very long time, for nearly two decades, and I don't want to be a manager any more. I'm over it.'

P6: 'I think that this course ... really made me sit back and think about .... where I could see myself going in the organisation.'

P7: 'I guess like before doing the course ... dare I say I had some career aspirations but I didn't exactly know what they were.

P9: 'It doesn't necessarily mean that I aspire to working in a higher level always and I don't think you have to be working in a substantially higher level to influence decision-making or to influence change so yeah so I'm happy. ... I feel comfortable where I am at the moment.

TABLE 9: Results overview.

\begin{tabular}{|c|c|c|c|}
\hline \multirow[t]{2}{*}{ Resources } & \multicolumn{2}{|c|}{ Quantitative } & \multirow[t]{2}{*}{ Qualitative } \\
\hline & Strong & Moderate & \\
\hline Agentic & $\begin{array}{l}\text { Overcoming opposition } \\
\text { Increased } \\
\text { resourcefulness } \\
\text { Coping abilities } \\
\text { Problem solving }\end{array}$ & $\begin{array}{l}\text { Solving difficult } \\
\text { problems } \\
\text { Dealing with } \\
\text { unexpected events } \\
\text { Solving intractable } \\
\text { problems } \\
\text { Dealing with } \\
\text { unexpected issues }\end{array}$ & $\begin{array}{l}\text { Increasing } \\
\text { confidence } \\
\text { Creating a positive } \\
\text { environment }\end{array}$ \\
\hline Relational & $\begin{array}{l}\text { Availability of helpful } \\
\text { people }\end{array}$ & $\begin{array}{l}\text { Availability of reliable } \\
\text { people } \\
\text { Assistance when } \\
\text { overwhelmed by } \\
\text { demands }\end{array}$ & $\begin{array}{l}\text { Finding networks } \\
\text { Notable people } \\
\text { Broadening } \\
\text { horizons }\end{array}$ \\
\hline Affective & - & - & $\begin{array}{l}\text { Clarifying career } \\
\text { options }\end{array}$ \\
\hline
\end{tabular}

to do so, it needed to develop a leadership development programme evaluation that focused on these resources and was suitable for use in the health and human services sector. It sought to extend this evaluation beyond short-term satisfaction measures to capture outcomes over time. The results of this study demonstrated a partial increase in target outcomes amongst participants in the DHHS development programme. In this, it also partially supported the Roberts et al. (2005) model of agentic, relational and positive affective resources.

Participants showed an increase in positive agentic resources: confidence and self-efficacy. Self-efficacy has been described as the positive organisational concept with the strongest claim against the criteria of 'valid measurement, ease of development and potential management for performance development' (Luthans, 2002b). Whilst Bandura (1997) differentiates the terms 'self-efficacy' and 'confidence', the participants in the development programme used the latter word in the sense of being confident in their ability to act to produce successful outcomes within the context of their workplace environment. Participation in the development programme also increased the sense of operating in a more positive organisational environment, in spite of the impact of staff downsizing. The manner in which participants related 
their sense of increased confidence to their organisational environment supports the idea of leadership learning as occurring through a process of participation and reflection, that builds on knowledge and experience, and occurs within context (Kempster, 2009a).

The GSES was effective in measuring the change in positive agentic resources before and after participation in the DHHS leadership development programme. The qualitative component of the study was valuable in articulating how the participants themselves understood the impact of the development programme. These shared reflections provide insight into their process of leadership learning and how this related to their role within the DHHS. The outcome was an increase their resources for leadership, as being confident is an attribute of an effective leader and manager (Kouzes \& Posner, 2007).

The evaluation also found an increase in positive relational resources: finding networks, having contact with notable people and broadening horizons. Here the quantitative data was less emphatic than the qualitative, which demonstrated that some of the most powerful and enduring outcomes of the DHHS development programme were the supportive relationships formed between participants. The qualitative data also showed the importance of interaction with more senior staff, described as 'notable people' (Kempster, 2009b) to inspire leadership learning. A stronger sense of horizontal and vertical connectedness within the organisation had the effect of 'broadening the horizons' of participants as they gained a greater understanding of their role in relation to others. It may be that the BSSS was not the optimum measure for this set of resources, in this context, and further research is required in order to determine if a suitable replacement may be found amongst the many social support surveys available (Hietzmann \& Kaplan, 1988).

The qualitative data also emphasised the importance of the workplace activities associated with the development programme in providing opportunities for growing these supportive relationships. The workplace activities were intended to promote observational learning through shadowing (Kempster, 2009b), one-to-one interactive learning through coaching (Brockbank \& McGill, 2006) and group learning through action learning (Rigg, 2006). The social and emotional support that participants reported as resulting from these experiences, however, provided relational resources upon which they could draw, sometimes well beyond the timeframe of the development programme itself.

With regard to affective resources, the quantitative data showed no change in the level of positive orientation towards the job in this study. At the same time, qualitative data indicated that there was a clarification of career options. Whilst there was no noticeable increase in job satisfaction, there was considerable reflection on whether the particular job was the best 'fit' for the individual. These results require more investigation. On the one hand, the results may reflect the stress of working in a 'downsizing environment' (Noer, 2009); on the other hand, there may be a deficit in the capture of job affect by the survey instrument. There is some debate about the ability of single items to capture job satisfaction (European Foundation for the Improvement of Living and Working Conditions, 2007; Wanous, Reichers \& Hudy, 1997). This may be tested by a comparison of the following year results with this first year, as those results become available.

The mixed-method research approach added to the explanatory power of the evaluation through triangulation of the quantitative and qualitative measures. Whilst the GSES measured an increase in self-efficacy, interview data provided insight into the participants' understanding of how this had occurred and what it meant in their workplace environment. Interviews also captured the strength of the perceived increase in relational resources in a way the BSSS did not. Where the survey question on affective resources did not register a significant result the qualitative data suggested explanations for this outcome. The mixed-method approach used in this study supported the assertion that different types of inquiry are sensitive to different real-world nuances (Patton, 2002). However, the ability of the evaluation to undertake qualitative interviews into the future will depend on resources becoming available. The ability to continue a mixed-method approach is limited and may be best treated as an addition to the evaluation that may be called upon if further clarification of results is required.

\section{Limitations of the study}

Both the quantitative and qualitative methods used relied upon the perceptions of the development programme participants, rather than a variety of data sources such as participants' staff, supervisors or clients and patients. This method was chosen as it enabled participants to contribute to the evaluation with minimal effort, possibly increasing response rates. It also allowed for a potential bias in the results. Whilst this could be partially controlled for in future studies, without significantly altering the methodology, by the inclusion of two questions from the Crowne-Marlowe social desirability scale (Donaldson \& Grant-Vallone, 2002), it represents a limitation in the current study. In addition, whilst the survey questionnaires were all administered at a consistent interval from the time of participation in the development programme course, the follow-up qualitative interviews were undertaken at varying time periods, between one and two years after participants had engaged with the programme. This limited their explanatory strength. Finally, the selection of subjects for interviewing was somewhat limited as only $26 \%$ of those approached consented to participate.

Studies show that the link between self-efficacy and social support can be mutually reinforcing, with social support enabling self-efficacy and self-efficacy cultivating social support, depending on the context (Schwartzer \& Knoll, 2007). Until more advanced statistical techniques are applied, these interactions will go unexplored, within the context of the DHHS development programme evaluation. 


\section{Conclusion}

The results of the development programme evaluation indicated that DHHS staff experienced a moderate increase in self-efficacy, a weak increase in social support and no change in job satisfaction. Participant self-confidence increased and career options became clearer, through contact with wider networks that included senior colleagues and other influential 'notable people' to broaden understanding (horizons) and create a more positive organisational environment. The mixed-method approach assisted in the development of an evaluation suitable to the context of the development programme. The quantitative research provided support for use of the GSES in capturing some of these changes and, more broadly, for the theoretical framework developed by Roberts et al. (2005). The BSSS was less effective as a measure for this set of resources, in this context, and further research is required. A need for further research into quantitative measures that may capture increase in positive affective resources has also been flagged. The qualitative research provided support for the position that leadership development is a vital component in meeting the challenges facing the health system (Health Workforce Australia, 2012) as participants drew upon peer networks and senior leadership for practical and inspirational support in the delivery of services to the Tasmanian public. The benefits of workplace learning are not only found at individual level, however, as the development of peer-led and other 'in-house' activities have been recognised as a costeffective approach for leadership development within health and human services (McPherson, 2010).

\section{Acknowledgements}

The authors would like to thank Mick Bendor and Heather Stokes for research assistance.

\section{Competing interest}

The authors declare that they have no financial or personal relationships that may have inappropriately influenced them in writing this article.

\section{Authors' contributions}

E.A.S. (University of Tasmania) was the project leader on this work, responsible for research design, the quantitative survey, literature review and analysis. P.V.D. (University of Tasmania) provided qualitative survey design and analysis. Both authors contributed to writing the article.

\section{References}

Australian Institute of Health and Welfare. (2012). Health expenditure Australia 2010 11. Health and welfare expenditure series. (Vol. 47, cat. no. HWE 56). Canberra, ACT, Australia.

Avolio, B.J., Luthans, F., \& Youssef, C.M. (2007). Psychological capital: Developing the human competitive edge. New York, NY: Oxford University Press.

Bandura, A. (1997). Self-efficacy: The exercise of control. New York, NY: Freeman.

Black, A.M., \& Earnest, G.W. (2009). Measuring the outcomes of leadership development programs. Journal of Leadership and Organizational Studies, 16 184-196. http://dx.doi.org/10.1177/1548051809339193

Bolden, R. (2011). Distributed leadership in organizations: A review of theory and research. International Journal of Management Reviews, 13, 251-269. http:// dx.doi.org/10.1111/j.1468-2370.2011.00306.x
Braithwaite, J., Skinner, C.A., \& Doery, M.L. (2011). A values-based health system. Medical Journal of Australia, 194(5), 259-262.

Brockbank, A., \& McGill, I. (2006). Facilitating reflective learning through mentoring and coaching. London, UK: Kogan Page.

Charmaz, K. (2006). Constructing grounded theory: A practical guide through qualitative analysis. Thousand Oaks, CA: Sage Publications.

Council of Australian Governments. (2011). National health reform agreement. Retrieved April 26, 2013, from http://www.federalfinancialrelations.gov.au/ content/npa/health_reform/national-agreement.pdf

Department of Health and Human Services. (2012). Annual report 2011-12. Hobart, TAS, Australia.

Development Guild/DDI. (2002). Evaluating outcomes and impacts: A scan of 55 leadership programs. Brookline, MA: W.K. Kellogg Foundation.

DiCicco-Bloom, B., \& Crabtree, B. (2006). The qualitative research interview. Medica Education, 40(4), 314-321. http://dx.doi.org/10.1111/j.1365-2929.2006.02418.x PMid:16573666

Dickson, G. (2007). The pan-Canadian health leadership capability framework project. Ontario, Canada: Centre for Health Leadership and Research.

Donaldson, S.I., \& Grant-Vallone, E.J. (2002). Understanding self-report bias in organizational behavior research. Journal of Business and Psychology, 17(2), 245260. http://dx.doi.org/10.1023/A:1019637632584

Doyle, L., Brady, M., \& Byrne, G. (2009). An overview of mixed methods research. Journal of Research in Nursing, 14, 175-185. http://dx.doi. org/10.1177/1744987108093962

Edwards, R., Austen, D., \& Altpeter, M. (1998). Managing effectively in an environment of competing values. In R. Edwards, J. Yankey, \& M. Altpeter (Eds.), Skills for Effective Management of Nonprofit Organizations (pp. 5-21). Washington, DC: National Association of Social Workers. PMid:9934038

Emmerik, I.J.H.V., \& Euwema, M.C. (2008). The aftermath of organizational restructuring: Destruction of old and development of new social capital. Journal of Manageria Psychology, 23(7), 833-849. http://dx.doi.org/10.1108/02683940810896367

European Expert Group on Health in Restructuring. (2009). Health in restructuring: Innovative approaches and policy recommendations. Bremen, Germany: University of Bremen.

European Foundation for the Improvement of Living and Working Conditions. (2007). Measuring job satisfaction in surveys - Comparative analytical report. Dublin, Ireland: Eurofound.

French, S., \& Holden, T. (2012). Positive organizational behavior: A buffer for bad news. Business Communication Quarterly, 75(2), 208-220. http://dx.doi. org $/ 10.1177 / 1080569912441823$

Grove, J.T., Kibel, B.M., \& Haas, T. (2005). EvaluLEAD: A guide for shaping and evaluating leadership development programs. Oakland, CA: The Public Health Institute.

Hancock, H., \& Campbell, S. (2006). Impact of the leading an empowered organisation program. Nursing Standard, 20(19), 41-48. http://dx.doi.org/10.7748/ ns2006.01.20.19.41.c4043

Hannum, K., Martineau, J., \& Reinelt, C. (Eds.). (2007). The handbook of leadership development evaluation. San Francisco, CA: Jossey-Bass.

Health Workforce Australia. (2012). Leadership for the sustainability of the health system: Part 1 - a literature review. Adelaide, Australia: Health Workforce Australia.

Health Workforce Australia. (2013). Australian health leadership framework Retrieved August 14, 2013, from http://www.hwa.gov.au/sites/uploads/HealthLEADS-Australia-A4-FINAL.pdf

Hietzmann, C.A., \& Kaplan, R.M. (1988). Assessment of methods for measuring social support. Health Psychology, 7(1), 75-109. http://dx.doi.org/10.1037/02786133.7.1.75

Jick, T.D. (1979). Mixing qualitative and quantitative methods: Triangulation in action. Administrative Science Quarterly, 24(4), 602-611. http://dx.doi. org/10.2307/2392366

Johnson, R., Onwuegbuzie, A., \& Turner, L. (2007). Toward a definition of mixed dx.doi.org/10.1177/1558689806298224

Kapikiran, S., \& Kapikiran, N. (2010). The validity and reliability of the Perceived Available Support Scale. Ankara University, Journal of Faculty of Educational Sciences, 43(2), 51-73.

Kempster, S. (2009a). How managers have learnt to lead: Exploring the development of leadership practice. Basingstoke, UK: Palgrave MacMillan. http://dx.doi. org/10.1057/9780230234741, PMCid:PMC2798646

Kempster, S. (2009b). Observing the invisible. Journal of Management Development, 28(5), 439-456. http://dx.doi.org/10.1108/02621710910955976

Kosimbei, G., Hanson, K., \& English, M. (2011). Do clinical guidelines reduce clinician dependent costs? Health Research Policy and Systems, 9(24). Available from http://www.health-policy-systems.com/content/9/1/24 PMid:21679458

Kouzes, J.M., \& Posner, B.Z. (2007). The leadership challenge. (4th edn.). San Francisco, CA: Jossey Bass.

Kvale, S. (1996). Interviews: An introduction to qualitative research interviewing. Thousand Oaks, CA: Sage Publications.

Lee, G., \& Teo, A. (2005). Organizational restructuring: Impact on trust and work satisfaction. Asia Pacific Journal of Management, 22, 23-29. http://dx.doi. org/10.1007/s10490-005-6416-6 
Leech, N., \& Onwuegbuzie, A. (2009). A typology of mixed methods research designs. Qual Quant, 43, 265-275. http://dx.doi.org/10.1007/s11135-007-9105-3

Liu, W.K., \& Lee, Y.-s. (2012). Assessment of cultural dimensions, leadership behaviors and leadership self-efficacy: Examination of multinational corporations in Taiwan. International Proceedings of Economics Development and Research, 28, 199-204.

Luszczynska, A., Scholz, U., \& Schwarzer, R. (2005). The General Self-Efficacy Scale: Multicultural validation studies. The Journal of Psychology, 139(5), 439-457. http://dx.doi.org/10.3200/JRLP.139.5.439-457

Luthans, F. (2002a). The need for and meaning of positive organizational behavior. Journal of Organizational Behavior, 23, 695-706. http://dx.doi.org/10.1002/ job.165

Luthans, F. (2002b). Positive organizational behavior: Developing and managing psychological strengths. The Academy of Management Executive, 16(1), 57-72.

Luthans, F., Youssef, C.M., \& Avolio, B.J. (2007a). Psychological capital. New York, NY: Oxford University Press.

Luthans, F., Youssef, C.M., \& Avolio, B.J. (2007b). Psychological capital: Investing and developing positive organizational behavior. In D. Nelson, \& C.P. Cooper (Eds.) Positive organizational behavior (pp. 9-24). London, UK: Sage Publications. http://dx.doi.org/10.4135/9781446212752.n2

McLean, S., \& Moss, G. (2003). They're happy, but did they make a difference? Applying Kirkpatrick's framework to the evaluation of a national leadership program. The Canadian Journal of Program Evaluation, 18(1), 1-23.

McPherson, B. (2010). Low-cost high-quality leadership development: A model for an affordable management-development programme. Training and Management Development Methods, 24, 01.01-01.05.

NHS Institute for Innovation and Improvement. (2010). NHS leadership framework: $A$ summary. Retrieved April 11, 2013, from http://www.leadershipacademy.nhs.uk/ discover/leadership-framework/

Noer, D.M. (2009). Healing the wounds: Overcoming the trauma of layoffs and revitalizing downsized organizations. San Francisco, CA: Jossey-Bass.

O’Byrne, M. (2011). Health budget savings. Tasmanian Government Media Release. Hobart, TAS, Australia: Tasmanian State Government.

O'Byrne, M. (2012). Keeping health strong. Tasmanian Government Media Release. Hobart, TAS, Australia: Tasmanian State Government.

Onwuegbuzie, A.J., \& Leech, N.L. (2005). On becoming a pragmatic researcher: The importance of combining quantitative and qualitative research methodologies. International Journal of Social Research Methodology, 8(5), 375-387.

Organisation for Economic Co-operation and Development (OECD). (2011). Health at a glance 2011: OECD indicators. Retrieved April 11, 2013. http://dx.doi. org/10.1787/health_glance-2011-en

Patton, M.Q. (2002). Qualitative research and evaluation methods. Thousand Oaks, CA: Sage Publications.

Quinn, R.E. (1988). Beyond rational management: Mastering the paradox and competing demands of high performance. San Francisco, CA: Jossey-Bass.

Quinn, R.E. (2005). Moments of greatness: Entering the fundamental state of leadership. Harvard Business Review, 83(7/8), 74-83.

Rigg, C. (2006). Understanding the organizational potential of action learning. In C. Rigg, \& S. Richards (Eds.), Action learning, leadership and organizationa development in public services (pp. 41-51). New York, NY: Routledge.
Roberts, L.M., Dutton, J.E., Spreitzer, G.M., Heaphy, E.D., \& Quinn, R.E. (2005). Composing the reflected best-self portrait: Building pathways for becoming extraordinary in work organizations Academy of Management Review 30(4), 712extraordinary in work organizations Academy of Manage

Russon, C., \& Reinelt, C. (2004). The results of an evaluation scan of 55 leadership development programs. Journal of Leadership and Organizational Studies, 10(3), 104-107. http://dx.doi.org/10.1177/107179190401000309

Scholz, U., Dona, B. G., Sud, S., \& Schwarzer, R. (2002). Is general self-efficacy a universal construct? European Journal of Psychological Assessment, 18(3), 242251. http://dx.doi.org/10.1027//1015-5759.18.3.242

Schulz, U., \& Schwarzer, R. (2003). Social support and coping with illness: The Berlin Social Support Scales. Diagnostica, 49, 73-82. http://dx.doi.org/10.1026//00121924.49.2.73

Schwarzer, R., Bäßler, J., Kwiatek, P., Schröder, K., \& Zhang, J.X. (1997). The assessment of optimistic self-beliefs: Comparison of the German, Spanish, and Chinese
versions of the General Self-Efficacy Scale. Applied Psychology, 46(1), 69-88. versions of the General Self-Efticacy Scale. Applied Px.doi.org/10.1111/j.1464-0597.1997.tb01096.x

Schwarzer, R., \& Jerusalem, M. (1995). Generalized self efficacy scale. In J. Weinman, S. Wright, \& M. Johnston (Eds.), Measures in health psychology: A user's portfolio (pp. 35-37). Windsor, UK: NFER-Nelson.

Schwartzer, R., \& Knoll, N. (2007). Functional roles of social support within the stress and coping process: A theoretical and empirical overview. International Journa of Psychology, 42(4), 243-252. http://dx.doi.org/10.1080/00207590701396641

Schwarzer, R., \& Leppin, A. (1988). Social support: the many faces of helpful social interactions. International Journal of Educational Research, 12(3), 333-345. http://dx.doi.org/10.1016/0883-0355(88)90010-9

Shannon, E., \& Burchill, T.A. (2013). 'Shaping our workforce': A Tasmanian development program. Australian Health Review, 37(1), 131-133. http://dx.doi. org/10.1071/AH12142, PMid:23369870

Shannon, E., Holden, J., \& Van Dam, P. (2012). Implementing national health reform is organisational culture the key? In Conference Proceedings: Australian Political Studies Association Conference (pp. 883-896). Hobart, TAS, Australia: Australian Political Studies Association Conference.

Shannon, E., Van Dam, P., \& Stokes, H. (2012). Building resilience in a professional services community: The role of leadership development. In Conference Proceedings: 52nd Annual Adult Learning Australia Conference: Lifelong learning = resilient communities (pp. 37-44). Byron Bay, NSW, Australia: Adult Learning Australia Inc.

Swanson, V., \& Power, K. (2001). Employees' perceptions of organizational restructuring: The role of social support. Work and Stress, 15(2), 161-178. http:// dx.doi.org/10.1080/02678370110066995

Tod, A. (2006). Interviewing. In K. Gerrish, \& A. Lacey (Eds.), The research process in nursing (pp. 337-352). Oxford, UK: Blackwell Publishing.

Van Beek, A., \& Gerritsen, D. (2010). The relationship between organizational culture of nursing staff and quality of care for residents with dementia: Questionnaire of nursing staff and quality of care for residents with dementia: Questionnaire
surveys and systematic observations in nursing homes. International surveys and systematic of Nursing Studies, 47(10), 1274-1282. http://dx.doi.org/10.1016/j. Journal of Nursing Studies, 47(10),
ijnurstu.2010.02.010, PMid:20371058

Wanous, J.P., Reichers, A.E., \& Hudy, M.J. (1997). Overall job satisfaction: How good are single-item measures? Applied Psychology, 82(2), 247-252. http://dx.doi. org/10.1037/0021-9010.82.2.247

World Health Organization (WHO). (2010). Health systems financing. The World Health Report. Geneva, Switzerland. 